\title{
Time course of response to prednisolone in chronic airflow obstruction
}

\author{
JONATHAN WEBB, T J H CLARK, AND CLAIR CHILVERS \\ From the Respiratory Function Laboratory, Guy's Hospital, London
}

\begin{abstract}
Nineteen patients with chronic airflow obstruction measured their morning and evening peak expiratory flow (PEF) daily for 28 days. A placebo was taken for the first week and prednisolone $20 \mathrm{mg}$ twice daily was taken for the last three weeks. The mean PEF in 13 patients who responded to prednisolone reached a maximum after eight days' treatment. The majority of the 19 patients had asthma and were thought to represent a typical cross section of patients who would be considered for a trial of oral corticosteroids. Most responsive patients will achieve a maximum response within eight days.
\end{abstract}

Patients with chronic airflow obstruction may improve with corticosteroid treatment and the idea of a trial of corticosteroids was introduced by Walsh and Grant. ${ }^{1}$ The value of corticostervids to patients with chronic airflow obstruction not thought to be caused by asthma is much more dubious. ${ }^{2}$ However, in an individual patient it is usually impossible to predict the presence or absence of corticosteroid responsiveness and for this reason many will require a trial of corticosteroids. The time course of the response to oral corticosteroids has not been adequately defined and uncertainty exists about the optimum length of such a trial. For this reason we have undertaken a prospective trial of corticosteroids in 19 patients with chronic airflow obstruction to investigate the time course of the response. The airflow obstruction was caused by asthma in most of the patients and in the remainder asthma was thought to contribute in part to the airflow obstruction.

\section{Methods}

Patients were selected for a trial of corticosteroids if they had airflow obstruction that had been present for at least three months and which had failed to respond adequately to bronchodilator therapy. None of the patients had previously been on long-term corticosteroids or had a short course of corticosteroids during the previous three

Address for reprint requests: Dr J Webb, Respiratory Laboratory, Brook General Hospital, Shooter's Hill Road, London SE18. months. Details of the 19 patients are shown in the table.

Each patient was seen by one of us (JW) and shown how to use a peak flow gauge (Airmed Ltd). Three readings of peak expiratory flow (PEF) were recorded at approximately the same time each morning soon after rising and again before retiring each evening for four weeks. Most patients were using a salbutamol aerosol during the trial and they were asked not to use their aerosol for a minimum of four hours before recording their peak flow. Four bottles of tablets were given to the patient, marked week $1,2,3$, and 4 . Week 1 bottle contained placebo tablets, and weeks 2,3 , and 4 contained $5 \mathrm{mg}$ prednisolone tablets. Four tablets $(20 \mathrm{mg})$ were taken each morning and evening.

A graph of the PEF was plotted for each patient over the four-week period. The time taken to reach an improved level of PEF was assessed by eye by one of us (JW) and by an independent observer.

\section{STATISTICAL ANALYSIS}

Initial inspection of the data revealed considerable differences in variability in each patient's PEF readings during the first week of the trial. A logarithmic transformation was found to stabilise the variance.

Differences in response to treatment at different times of day and over the four-week period of the trial were investigated using an analysis of vari- 
Table Clinical details of the 19 patients

\begin{tabular}{|c|c|c|c|c|c|c|c|}
\hline Patient & Age & Sex & Cigarettes/history & Skin test & $\begin{array}{l}\text { PEF } \% \\
\text { predicted }\end{array}$ & Diagnosis & $\begin{array}{l}\% \text { Response to } \\
\text { prednisolone }\end{array}$ \\
\hline 1 & 59 & $\mathbf{M}$ & $\begin{array}{l}60 / \text { day until age } 52 \text { yr when wheeze and dyspnoea } \\
\text { began }\end{array}$ & $-\mathbf{v e}$ & 62 & $\mathrm{CB}, \mathrm{A}$ & $<10$ \\
\hline 2 & 38 & $\mathbf{M}$ & Non-smoker. Hayfever and asthma began at age $36 \mathrm{yr}$ & + ve & 56 & $\mathbf{A}$ & 75 \\
\hline 3 & 67 & $\mathbf{M}$ & $\begin{array}{l}20 / \text { day. Cough and sputum } 25 \mathrm{yr} \text {. Wheezy since } \\
\text { age } 50 \mathrm{yr} \text {. }\end{array}$ & $-\mathrm{ve}$ & 24 & $\mathrm{CB}, \mathrm{A}$ & 18 \\
\hline 4 & 62 & $\mathbf{M}$ & $25 /$ day. "Chesty" as a child. Wheezy $5 \mathrm{yr}$. & $+\mathrm{ve}$ & 55 & A, CB & 16 \\
\hline 5 & 32 & $\mathbf{M}$ & $20 /$ day. Asthma as a child and returned at age $28 \mathrm{yr}$. & $+\mathrm{ve}$ & 68 & $\mathbf{A}$ & 20 \\
\hline 6 & 41 & $\mathbf{M}$ & $20 /$ day. Rhinitis and wheeze since age $26 \mathrm{yr}$. & $-\mathrm{ve}$ & 59 & $\mathbf{A}$ & 23 \\
\hline 7 & 36 & $\mathbf{M}$ & $20 /$ day. Wheeze began at age 26 yr. & +ve & 51 & $\mathbf{A}$ & $<10$ \\
\hline 8 & 49 & $\mathbf{M}$ & 20/day. Dyspnoea since age 40 yr. Occasional wheeze. & tre & 46 & $\mathbf{E}, \mathbf{A}$ & 10 \\
\hline 9 & 54 & $\mathbf{M}$ & Non-smoker. Asthma since age 14 yr. & tre & 51 & $\mathbf{A}$ & 27 \\
\hline 10 & 52 & $\mathbf{M}$ & $\begin{array}{l}15 / \text { day until age } 50 \mathrm{yr} \text {. Asthma until age } 11 \mathrm{yr} \text { and } \\
\text { age } 30 \mathrm{yr} \text {. until now. }\end{array}$ & tre & 36 & $\mathbf{A}$ & 77 \\
\hline 11 & 71 & $\mathbf{F}$ & 40/day. Chronic wheezy dyspnoea for $10 \mathrm{yr}$. & $-\mathbf{v e}$ & 47 & $\mathrm{CB}, \mathrm{A}$ & $<10$ \\
\hline 12 & 56 & $\mathbf{M}$ & 10/day. Wheezy dyspnoea since age $30 \mathrm{yr}$. & $+\mathrm{ve}$ & 39 & $\mathrm{~A}, \mathrm{CB}$ & 20 \\
\hline 13 & 56 & $\mathbf{M}$ & 20/day. Cough, sputum, and wheeze since age $40 \mathrm{yr}$. & $-v e$ & 41 & $\mathrm{CB}, \mathrm{A}, \mathrm{E}$ & $<10$ \\
\hline 14 & 66 & $\mathbf{M}$ & $20 /$ day. Cough, sputum, and wheeze since age $45 \mathrm{yr}$. & - ve & 18 & CB. A & 34 \\
\hline 15 & 66 & $\mathbf{M}$ & $15 /$ day. Wheezy cough since age $30 \mathrm{yr}$. & $+v e$ & 24 & $\mathrm{~A}, \mathrm{CB}$ & 13 \\
\hline 16 & 63 & $\mathbf{M}$ & $15 /$ day. Chronic wheezy dyspnoea since age $55 \mathrm{yr}$. & $-\mathrm{ve}$ & 53 & $\mathrm{CB}, \mathrm{A}$ & $<10$ \\
\hline 17 & 42 & $\mathbf{F}$ & Non-smoker. Wheezy dyspnoea began age 31 yr. & $+\mathrm{ve}$ & 34 & A & 16 \\
\hline 18 & 31 & $\mathbf{F}$ & $\begin{array}{l}\text { 10/day for three yr. Wheezy till age } 10 \text { and again } \\
\text { age } 17 \mathrm{yr} \text {. }\end{array}$ & $+\mathrm{ve}$ & 74 & $\mathbf{A}$ & $<10$ \\
\hline 19 & 30 & $\mathbf{F}$ & Non-smoker. Asthma and rhinitis since age $21 \mathrm{yr}$. & $+\mathrm{ve}$ & 55 & $\mathbf{A}$ & 36 \\
\hline
\end{tabular}

PEF $\%$ predicted = mean of 14 PEF readings during week on placebo expressed as a percentage of the predicted $P E F . A=$ asthma, $C B=$ chronic bronchitis, $\mathrm{E}=$ emphysema. The order is determined by the disease process thought to be responsible for most of the airflow obstruction.

ance. In order to establish whether or not there was a placebo effect readings on day seven were compared with readings on day one using a paired $t$ test. Response to treatment was measured by comparing the mean PEF readings during the third and fourth weeks of treatment with the mean PEF readings during the placebo week.

Response to corticosteroids was assessed firstly by using a $10 \%$ increase in PEF as a response criterion, and secondly by carrying out a $t$ test on the untransformed data and taking a significance level of one per cent.

\section{Results}

There was a considerable difference between morning and evening mean PEF readings over the four week period $(p<0.01)$. The evening PEF measurement was, on average, $6 \%$ higher than the morning PEF measurement $(95 \%$ confidence limits $5 \%$ and $8 \%$ ), and this difference remained effectively constant throughout the four-week period.

There was no difference in PEF on days one and seven of the first week $(p>0 \cdot 4)$, nor between the mean PEF values during the third and fourth weeks $(p>0 \cdot 8)$. The mean improvement in PEF between the first week and the third and fourth weeks was $18 \%(95 \%$ confidence limits $15 \%$ and $21 \%$ ).
Individual responses to treatment are shown in the table. The two criteria for determining individual response to treatment gave identical results in all patients. Thirteen patients showed an improvement in PEF of at least $10 \%$. Their mean PEF readings throughout the four-week period are shown in fig 1 . The maximum daily mean PEF occurred on the eighth day of treatment. The mean evening peak flow measurement was $10 \%$ higher than the mean morning peak flow measurement during the placebo weeks and $7 \%$ higher during the third and fourth weeks. This difference is not statistically significant $(\mathrm{p}>0 \cdot 1)$.

The two observers' assessments of the time taken to respond to treatment in individual trials agreed to within one day in nine patients and to within three days in the remaining four patients (range for the two observers one to 11 days). The average of the assessments for each patient is shown in fig 2 . In only one patient did the time taken to reach the improved PEF level exceed eight days.

\section{Discussion}

The patients reported are thought to represent a typical cross-section of patients who would be considered for a trial of corticosteroids. Most of the patients selected had unequivocal asthma. However, some patients with chronic obstructive 


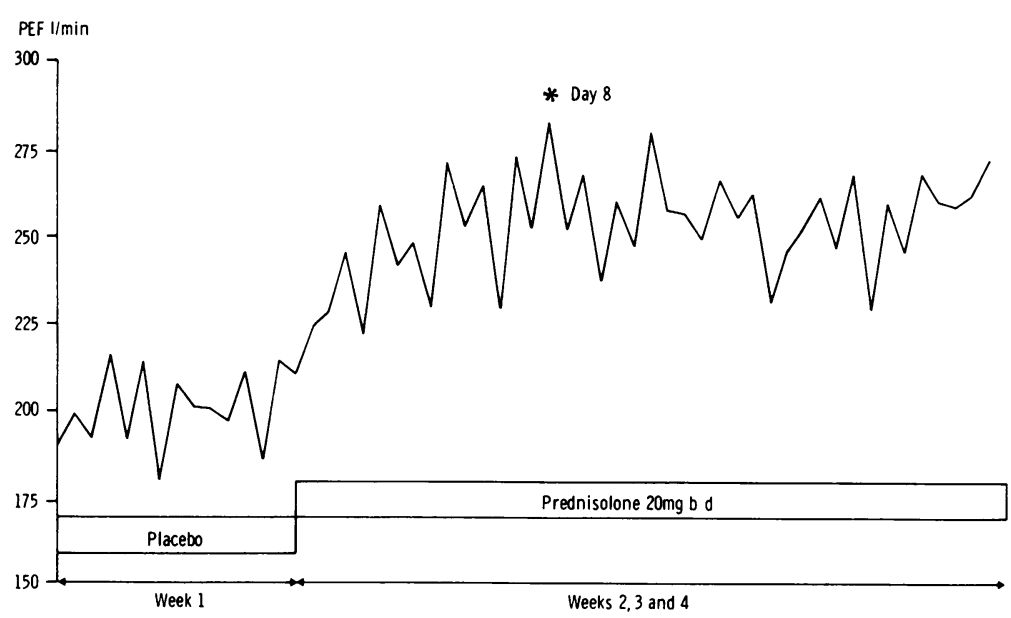

Fig 1 Mean PEF of 13 responsive patients throughout $a$ one-month trial of corticosteroids.

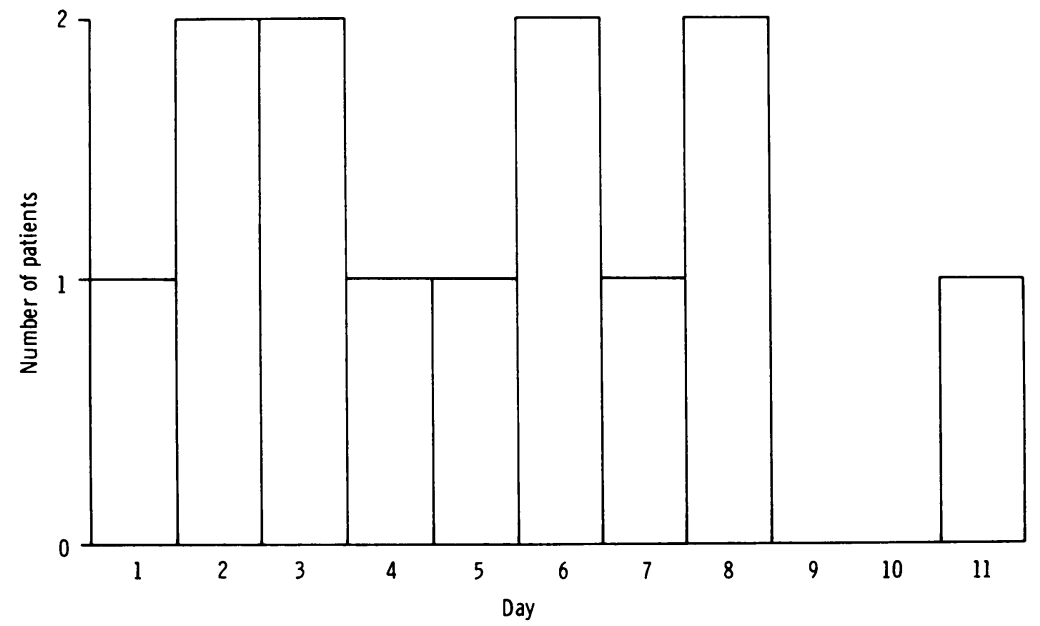

Fig 2 Time taken to reach the improved level of PEF in 13 responsive patients.

bronchitis and emphysema were included because it was not possible to exclude some degree of asthma contributing to their airflow obstruction.

The length of time required for a trial of corticosteroids will depend on the time taken to achieve a maximum response on a continuous dose of corticosteroids. Shenfield et $a l^{3}$ demonstrated a "striking response" to corticosteroids in six patients with chronic asthma during a one-week course of prednisolone $40 \mathrm{mg} /$ day. In five of the six patients, the best $\mathrm{FEV}_{1}$ was obtained on the seventh and final day of the trial. Crompton, ${ }^{4}$ in a group of 18 chronic asthmatic patients given a six-day course of $40 \mathrm{mg}$ of prednisolone a day, showed that the mean $\mathrm{FEV}_{1}$ for the 18 patients reached a maximum on the sixth and final day of the trial. These patients might have continued to improve if the trials had continued longer. The results of the 13 patients who responded to corticosteroids in this study indicate that the maximum response occurred on the eighth day. This would suggest that the length of time for a trial of corticosteroids should be at least eight days. The dose of $40 \mathrm{mg} /$ day used in our trials was arbitrary because the dose-response characteristics of airflow obstruction to corticosteroids has not been adequately defined.

The design of the trial should ideally incorporate a control period to establish a reliable baseline measurement. Ethically this control period cannot involve stopping treatment and so usual bronchodilator drugs should be continued during 
this period. We found that the cheaper peak flow meters now available are ideal for use in outpatient trials of corticosteroids.

There are points of interest arising from some of the trials performed in the 19 patients. Two patients, numbers 7 and 18, aged 36 and 31 years, both had chronic "extrinsic" asthma with positive skin tests. There was no subjective or objective evidence of any change in respiratory function while on corticosteroids in either of them. Patient 7 was seen again in the chest clinic six months later, taking no treatment with a peak flow of $480 \mathrm{l} / \mathrm{min}$. His peak flow had averaged approximately $290 \mathrm{1} / \mathrm{min}$ during treatment with prednisolone. This patient had moderate airflow obstruction when undergoing the trial of corticosteroids which failed to improve even though potential for considerable improvement was present. Failure to respond to corticosteroids was not the result of impaired absorption of prednisolone since his basal cortisol levels were depressed to $100 \mathrm{~nm} / 1$. The results from these two patients emphasise that not all asthmatic patients respond to corticosteroids. In contrast, three of the seven patients with airflow obstruction not thought to be caused predominantly by asthma responded to corticosteroids. This emphasises how difficult it is to predict which patient will respond to corticosteroids and explains why a group of patients selected for a trial of corticosteroids will inevitably include patients with different causes of airflow obstruction.

Diurnal variation in PEF is well recognised in asthma. The serum cortisol levels also drop in the early morning but continuous infusion of hydrocortisone does not abolish the dip in PEF. ${ }^{5}$ The results in this study show that supraphysiological doses of corticosteroids do not influence diurnal variation in either the corticosteroid responsive or non-responsive patients when considered as a group.
None of the 19 patients experienced an exacerbation of asthma on withdrawal from prednisolone and there were no serious side-effects during or after the three-week trial of corticosteroids. The details of the effects of $40 \mathrm{mg}$ of prednisolone daily for three weeks on the hypothalamic pituitary adrenal axis are reported elsewhere. ${ }^{6}$

In conclusion, we believe that the majority of patients with chronic airflow obstruction whose symptoms are not adequately controlled with bronchodilators should have a trial of corticosteroids lasting at least eight days. Not all patients with asthma respond to corticosteroids and a trial cannot be used as the sole criterion for diagnosis.

We should like to thank Dr SW Clarke and Dr $\mathrm{K}$ Marsh for allowing us to study their patients, Dr GM Cochrane for his helpful comments during preparation of this paper, and Mrs $\mathrm{J}$ Major for secretarial assistance.

\section{References}

1 Walsh SD, Grant IWB. Corticosteriods in treatment of chronic asthma. $\mathrm{Br}$ Med J 1966; 2:796802.

2 Cullen JH, Reidt WV. A study of the respiratory effects of prednisolone in diffuse airways obstruction. Am Rev Respir Dis 1960; 82:508-15.

3 Shenfield GM, Hodson ME, Clarke SW, Paterson JW. Interaction of corticosteroids and catecholamines in the treatment of asthma. Thorax 1975; 30:430-5.

4 Crompton GK. A comparison of responses to bronchodilator drugs in chronic bronchitis and chronic asthma. Thorax 1968; 23:46-55.

5 Soutar CA, Costello J, Ijaduola O, TurnerWarwick $M$. Nocturnal and morning asthma. Thorax 1975; 30:436-40.

6 Webb JR, Clark TJH. Recovery of plasma corticotrophin and cortisol levels after a three-week course of prednisolone. Thorax 1981; 35:22-4. 